\title{
Enhancing Frequency of Grid-connected Wind Farm using Energy Capacitor System and Trap RC Shunt Damper Strategies
}

\author{
Kenneth E. Okedu ${ }^{1,2, *}$ \\ 1: Department of Electrical and Computer Engineering, National University of Science and Technology, \\ PC 111, Muscat, Sultanate of Oman \\ 2: Department of Electrical and Electronic Engineering, University of Port Harcourt, P.M.B. 5323, Rivers \\ State, Nigeria
}

Received April 30, 2018; Accepted May 30, 2018; Published June 3, 2018

\begin{abstract}
In this paper, a combination of the conventional energy capacitor system and a proposed two-trap Resistor Capacitor (RC) shunt damper circuitry is used to stabilize a grid network made up of fixed speed wind turbines, steam turbines and hydro turbines. The energy storage system is connected to the terminals of the wind farm and has the capability of stabilizing the grid network during periods of wind speed change. The two-trap damper has the ability to mitigate the mechanical vibration of the wind turbine and increase its output and rotor speed acceleration during disturbances, so the turbine speed is reduced. Simulations were run using Power System Computer Aided Design and Electromagnetic Transient Including DC (PSCAD/EMTDC) environment, for scenarios where grid frequency control was not implemented and when frequency control was employed using the energy storage device. A further investigation was carried out in enhancing the performance of the grid network considering the proposed two-trap shunt DC damper control topology. The results show the improved performance of the variables of the wind turbine and the entire grid network during dynamics, due to the coordinated control strategies of the two-trap RC circuit and the energy capacitor system employed.
\end{abstract}

Keywords: Wind energy; Wind farm; Frequency; Grid; Wind turbine; Filters; RC damper

\section{Introduction}

Recently, the renewable energy technology has received more attention, because it not only has the potential to improve energy security, but also reduces the environmental impact of greenhouse gases. Hence, this type of energy is eco-friendly. The constant penetration of wind farms that are equipped with wind turbines into existing grid connected network, would definitely affect the frequency and stability of the entire power system. Power electronics technology is the main technology that enables the connection of renewable energy sources like wind and solar into the grid system [1-3]. They are used to interface the generated energy into the grid. However, these voltage source converters produce unwanted harmonics. As a result, filters are used to smoothen the output of the network.

With tremendous rise in renewable energy penetration into the grid system, there is bound to be disturbances in the power network. Consequently, the grid network and its 
control associates are becoming complex by day. The integration of wind power into existing power network causes frequency distortions due to the stochastic nature of the wind. A lot of papers have been presented in the literature regarding frequency control of the grid connected network. Traditionally, the automatic load frequency control can be used to maintain the grid system frequency by variation of the governor set points of the turbines connected to the network $[4,5]$. In the literature [6-8], the genetic algorithm strategy was proposed to control the load frequency in a mixed generation system, in order to maintain zero steady state error during grid disturbances. The major shortcoming of this approach is the presence of oscillations in the frequency deviations and a longer time to reach steady state for the power system variables. Another good approach to stabilize the frequency of a grid connected system is the utilization of adaptive notch filters [9-11]. The challenge in using this approach is that the measured signal frequency should remain constant and this is not the case with the use of wind energy system.

Usually, an Inductive Capacitive Inductive (LCL) filter is used to mitigate the switching harmonics emanating from a Voltage Source Converter (VSC) that is connected to the grid network. This is because they offer lower cost and are simple in nature [12]. For this reason, the LCL filter is employed in the integration of renewable sources in grid networks. With recent advancement in power electronics technology, the trap filters have been proposed as a good solution to suppress switching harmonics more than the traditional LCL filters [13]. The trap filter topology are smaller in size with low cost compared to earlier filter strategies.

In order to avoid the risk of instability in the grid connected VSC as a result of resonance in the capacitive and inductive components in the grid, it is necessary to consider damping. However, due to constant changes in the grid network variables, effective damping may not be realized using active damping control strategies alone [14]. Another solution to this problem may be to employ passive damping because it will improve the stability of the system [15], however, there must be large losses to be incurred [16].

Energy storage system can effectively mitigate oscillations in the power system, and hence could be used for frequency regulation. In the literature [17], additional power to achieve control of a grid connected network was provided by both internal and external energy storage devices. In [18], the energy capacitor system was used to stabilize grid voltage system, however, the shunt trap frequency control responses were not considered. Thus, the controllers of the energy capacitor system were not tested for robustness during grid dynamics. Reference [19] considered the use of a small value of series dynamic braking resistor in the stator of the wind turbine to improve the frequency of the power system.

The tripping of wind power generators i.e., grid connected wind turbines is most likely to avoid grid dynamics or transient disturbances [20]. This is not allowed in most countries, based on the recent grid codes. In this paper, the conventional Energy Capacitor System (ECS) technology is used to stabilize grid connected wind power and synchronous turbine systems. The ECS is used to achieve smoothing of the terminals of the distorted wind turbine variables in order to maintain steady supply of power despite the stochastic nature of the wind. In order to enhance the performance of the conventional wind farm frequency control ECS topology, a two-trap Resistor Capacitor (RC) shunt damper is proposed to work in combination with the ECS control system. The proposed two-trap shunt RC damper is used to improve the performance of the wind turbine during grid disturbances. The new control strategy also has the ability to reduce the speed 
excursion of the wind turbine and boost the turbine speed during grid dynamics. Besides, the proposed system effectively enhances the reactive power production of the VSC connected ECS external device, thus, improving its performance when there is grid disturbance. These effects would reduce the grid connected VSC losses and improve the overall performance of the system. In addition, the grid codes minimum frequency values stipulated in the operation of wind farms and power systems would be achieved, thus, avoiding the tripping of the wind turbines during grid disturbances. In this work, simulations were run for different scenarios in Power System Computer Aided Design and Electromagnetic Transient Including DC (PSCAD/EMTDC) platform [21]. In the first scenario, no frequency control was employed in the power system. The second scenario considered frequency control of the grid network, using the ECS topology, while the third scenario employs the proposed two-trap shunt RC damper to further enhance the performance of the ECS system. The presented results show the robustness of the proposed control strategy in enhancing the performance of the frequency and some other variables of the grid connected wind farm in the power network.

\section{Model System of Study}

The model system of study is shown in Figure 1, where the wind farm is made up of two aggregated wind turbines of total power rating 100 MVA connected to aggregated steam and hydro turbines of 50 MVA each.

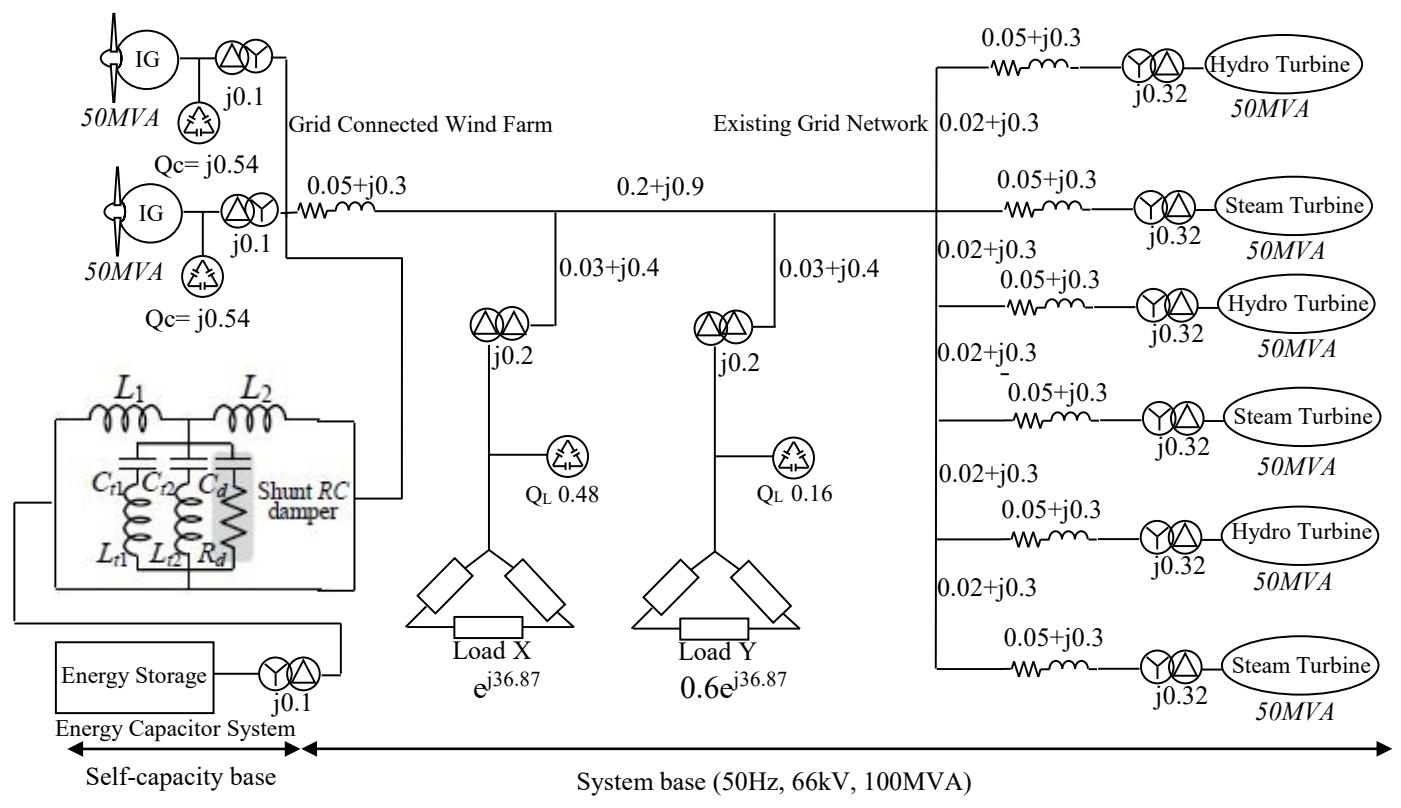

Figure 1. Model system of study

The ECS is connected at the terminals of the wind turbines via the proposed twotrap RC shunt circuitry in the wind farm as shown in Figure 1. Loads $\mathrm{X}$ and $\mathrm{Y}$ are connected between the bus bar connecting the wind farm and the steam and hydro synchronous generators. The power network is operating at $100 \mathrm{MVA}, 66 \mathrm{kV}$ and $50 \mathrm{~Hz}$ with the given line parameters. The two-trap shunt RC damper circuitry is connected 
between the terminals of the wind turbine and the VSC grid side of the ECS. The parameters of the wind turbine, steam and hydro turbines are given in Table 1. The excitation circuit parameters of the ECS and the proposed two-trap shunt RC damper are given in Tables 2 and 3, respectively.

Table 1. Parameters of the model system turbines

\begin{tabular}{|c|c|c|c|c|}
\hline $\begin{array}{c}\text { Generator } \\
\text { Type }\end{array}$ & $\begin{array}{c}\text { Steam } \\
\text { turbine }\end{array}$ & $\begin{array}{c}\text { Hydro } \\
\text { turbine }\end{array}$ & $\begin{array}{c}\text { Generator } \\
\text { Type }\end{array}$ & $\begin{array}{c}\text { Wind } \\
\text { turbine }\end{array}$ \\
\hline $\mathrm{MVA}$ & 200 & 200 & $\mathrm{MVA}$ & 100 \\
\hline $\mathrm{r}_{\mathrm{a}}(\mathrm{pu})$ & 0.003 & 0.003 & $\mathrm{r} 1(\mathrm{pu})$ & 0.01 \\
\hline $\mathrm{X}_{\mathrm{a}}(\mathrm{pu})$ & 0.102 & 0.130 & $\mathrm{x} 1(\mathrm{pu})$ & 0.1 \\
\hline $\mathrm{X}_{\mathrm{d}}(\mathrm{pu})$ & 1.651 & 1.200 & $\mathrm{Xmu}(\mathrm{pu})$ & 3.5 \\
\hline $\mathrm{X}_{\mathrm{q}}(\mathrm{pu})$ & 1.590 & 0.700 & $\mathrm{r} 21(\mathrm{pu})$ & 0.035 \\
\hline $\mathrm{X}_{\mathrm{d}}^{\prime}(\mathrm{pu})$ & 0.232 & 0.300 & $\mathrm{x} 21(\mathrm{pu})$ & 0.030 \\
\hline $\mathrm{X}_{\mathrm{q}}^{\prime}(\mathrm{pu})$ & 0.380 & & $\mathrm{r} 22(\mathrm{pu})$ & 0.014 \\
\hline $\mathrm{X}^{\prime \prime}{ }_{\mathrm{d}}(\mathrm{pu})$ & 0.171 & 0.220 & $\mathrm{x} 22(\mathrm{pu})$ & 0.098 \\
\hline $\mathrm{X}^{\prime \prime}{ }_{\mathrm{q}}(\mathrm{pu})$ & 0.171 & 0.250 & & \\
\hline $\mathrm{T}^{\prime} \mathrm{do}(\mathrm{sec})$ & 5.900 & 5.000 & & \\
\hline $\mathrm{T}^{\prime} \mathrm{qo}(\mathrm{sec})$ & 0.535 & & & \\
\hline $\mathrm{T}^{/ /} \mathrm{do}(\mathrm{sec})$ & 0.033 & 0.040 & & \\
\hline $\mathrm{T}^{\prime /} \mathrm{qo}(\mathrm{sec})$ & 0.078 & 0.050 & & \\
\hline $\mathrm{H}(\mathrm{sec})$ & 3.000 & 2.500 & & \\
\hline
\end{tabular}

Table 2. Parameters of the ECS excitation circuit

\begin{tabular}{|c|c|}
\hline Parameters & Ratings \\
\hline DC-link Voltage & $6.6 \mathrm{kV}$ \\
\hline DC-link Capacitor & $50,000 \mu \mathrm{F}$ \\
\hline Device for Power Converter & IGBT \\
\hline PWM Carrier Frequency & $1.05 \mathrm{kHz}$ \\
\hline low pass filter time constant & $30 \mathrm{sec}$ \\
\hline
\end{tabular}

Table 3. Parameters of the two-trap shunt RC damper

\begin{tabular}{|c|c|}
\hline Parameters & Ratings \\
\hline Line Inductor & $0.1 \mathrm{mH}$ \\
\hline Filter Capacitor & $2.15 / 0.21 \mu \mathrm{F}$ \\
\hline Damp Resistor & $5.4 \Omega$ \\
\hline DC-link Voltage & $6.6 \mathrm{kV}$ \\
\hline Damp Capacitor & $2.35 \mu \mathrm{F}$ \\
\hline Trap Inductors & $0.113 / 0.3 \mathrm{mH}$ \\
\hline
\end{tabular}

\section{Control Strategy of the FACTS Energy Storage Device}

Figure 2 shows the control structure of the grid connected VSC ECS, where a dq to abc transformation is done with an angle thetha that is calculated from the Phase Lock Loop (PLL) of the system. The effective grid voltage is compared with a reference value 
of $1.0 \mathrm{pu}$ that is then passed through a Proportional Integral (PI) controller system. The signal is further compared with a signal generator to generate six pulse reference signals, which are used for switching the Insulated Gate Bipolar Transistors (IGBTs) to achieve control of the wind farm system and the entire power network during grid disturbances. Also, the control structure and design for the inbuilt Low Pass Filter (LPF) of the ECS are shown in Figure 2. The reference signals are the grid active power and the wind turbine active power, respectively. The difference of the powers is fed through a PI system whose output is added to a constant gain value to generate signal that is compared with a triangular carrier signal generator. The output is thus used in the switching of the DC chopper circuit unit of the ECS system for charging and discharging limitations. The proposed connected two-trap shunt $\mathrm{RC}$ damper increases the mechanical power extracted from the drive train of the aggregated wind generator and reduces its speed excursion during dynamic periods. Also, since mechanical torque is proportional to the square of the stator voltage of the wind turbine, the effect would enhance the fast recovery of the turbine during grid disturbances.

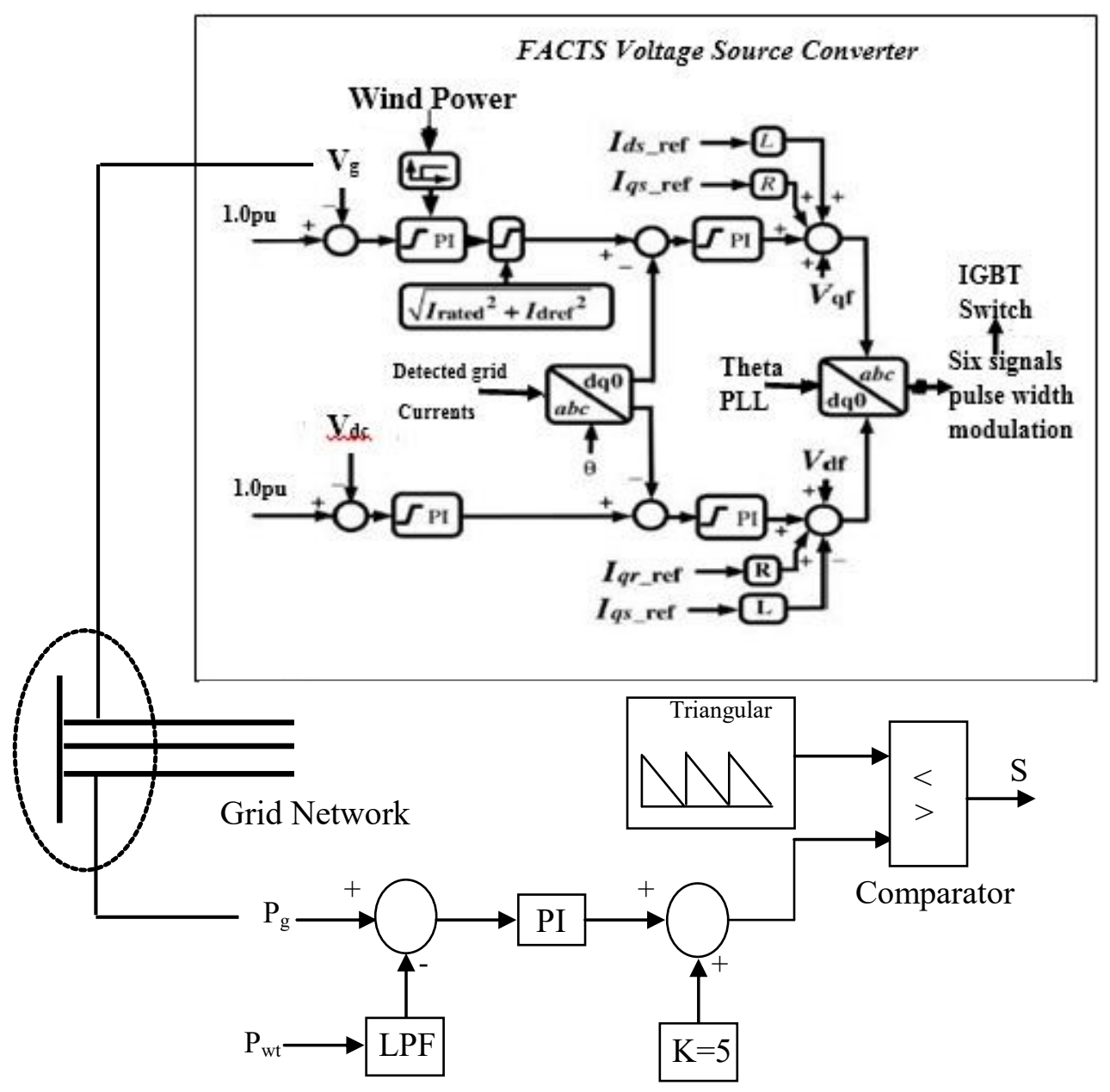

Figure 2. ECS and its associate controls 


\section{Space Vector Control of the ECS and the Trap Shunt RC Damper}

The control system of the three phase voltage source converter for the ECS shown in Figure 2 is based on space vector transformation. As seen from the figure, the detected three phase currents are $i_{a}, i_{b}$ and $i_{c}$, which are vectors that are equally spaced in $a b c$ clockwise sequence with respect to the grid, which is in stationary $a b c$ reference frame as given in equation (1) [22].

$$
\left[\begin{array}{l}
i_{a} \\
i_{b} \\
i_{c}
\end{array}\right]=\left[\begin{array}{c}
\hat{I} \cos (\omega t) \\
\hat{I} \cos (\omega t-2 \pi / 3) \\
\hat{I} \cos (\omega t+2 \pi / 3)
\end{array}\right]
$$

The transformation of these vectors into two phase stationary reference frames $\alpha \beta$ is shown in Figure 3 and their products are represented with $i_{\alpha}$ and $i_{\beta}$ in the clockwise direction in Figure 4.

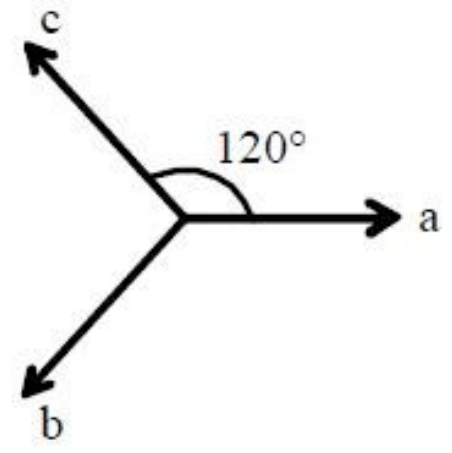

Figure 3. VSC abc stationary frame

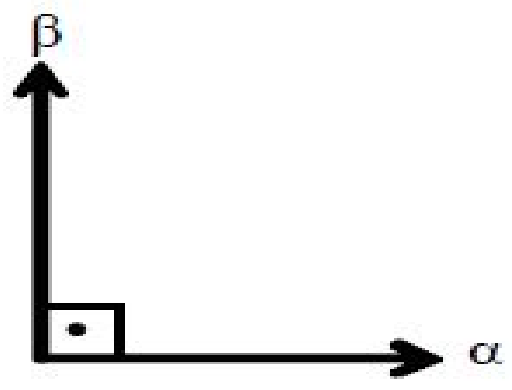

Figure 4. VSC $\alpha \beta$ stationary frame 
A further decoupling of the $a b c$ phase vectors based on the $\alpha$ and $\beta$ axis results in equation (2) with three unknown variables.

$$
\begin{gathered}
X_{2} i_{\alpha}=X_{3} i_{a}+X_{3} i_{b} \cos \left(\frac{4 \pi}{3}\right)+X_{3} i_{c} \cos \left(\frac{2 \pi}{3}\right) \\
X_{2} i_{\beta}=0+X_{3} i_{b} \sin \left(\frac{4 \pi}{3}\right)+X_{3} i_{c} \sin \left(\frac{2 \pi}{3}\right) \\
X_{2} i_{0}=k X_{3} i_{a}+k X_{3} i_{b}+k X_{3} i_{c}
\end{gathered}
$$

From equation (2), $X_{2}$ represents the $\alpha \beta$ frame magnitude, while $X_{3}$ represents the components of the $a b c$ frame. Putting equation (2) into matrix forms, gives

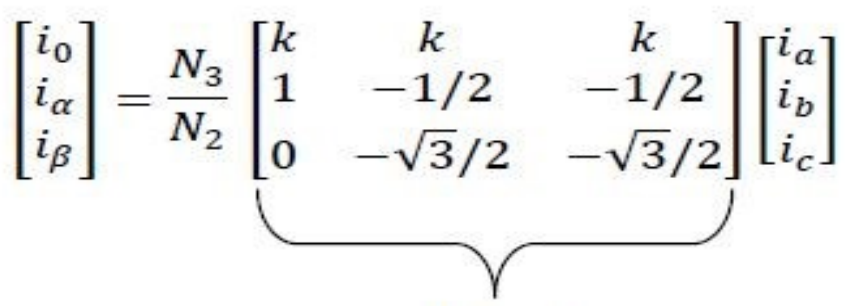

\section{$\left[T_{\alpha \beta 0}\right]$}

Considering the orthogonal condition, $\left[T_{\alpha \beta 0}\right]^{2}\left[T_{\alpha \beta 0}\right\rfloor=I_{3 \times 3}$, the transformation matrix $\left[T_{\alpha \beta 0}\right]$ and $X_{3} / X_{2}$ ratio are computed as shown in equation (4), where $\left[T_{\alpha \beta 0}\right]^{T}$ is the transpose of $\left[T_{\alpha \beta 0}\right]$ and $I_{3 \times 3}$ is a $3 \times 3$ identity matrix.

$$
\left[\begin{array}{l}
i_{0} \\
i_{\alpha} \\
i_{\beta}
\end{array}\right]=\sqrt{\frac{2}{3}}\left[\begin{array}{ccc}
1 / \sqrt{2} & 1 / \sqrt{2} & 1 / \sqrt{2} \\
1 & -1 / 2 & -1 / 2 \\
0 & \sqrt{3} / 2 & -\sqrt{3} / 2
\end{array}\right]\left[\begin{array}{l}
i_{a} \\
i_{b} \\
i_{c}
\end{array}\right]
$$

Equation (4) is known as the Clarke transformation and the vectors in both frames are the same, since equation (2) normalizes the transformation. This situation would lead to equation (5)

$$
i_{\alpha}{ }^{2}+i_{\beta}{ }^{2}+i_{0}{ }^{2}=i_{a}{ }^{2}+i_{b}{ }^{2}+i_{c}{ }^{2}
$$

It should be noted that zero sequence component is not utilized for the remaining transformation analysis, because it is ignored for simplicity. And the matrix would reduce to equation (6). 


$$
\left[\begin{array}{l}
i_{\alpha} \\
i_{\beta}
\end{array}\right]=\sqrt{\frac{2}{3}}\left[\begin{array}{ccc}
1 & -1 / 2 & -1 / 2 \\
0 & \sqrt{3} / 2 & -\sqrt{3} / 2
\end{array}\right]\left[\begin{array}{c}
i_{a} \\
i_{b} \\
i_{c}
\end{array}\right]
$$

If the frequency of rotation of the grid is $\omega_{g}$, then based on Fig. 5, the variables of the stationary $\alpha \beta$ frame can be expressed as equation (7). Also, the variables of the stationary reference frame in equation (6) can be transformed into synchronous frame based on equation (8) with displacement clockwise direction angle $\theta$ between the ranges of 0 to $2 \pi$.

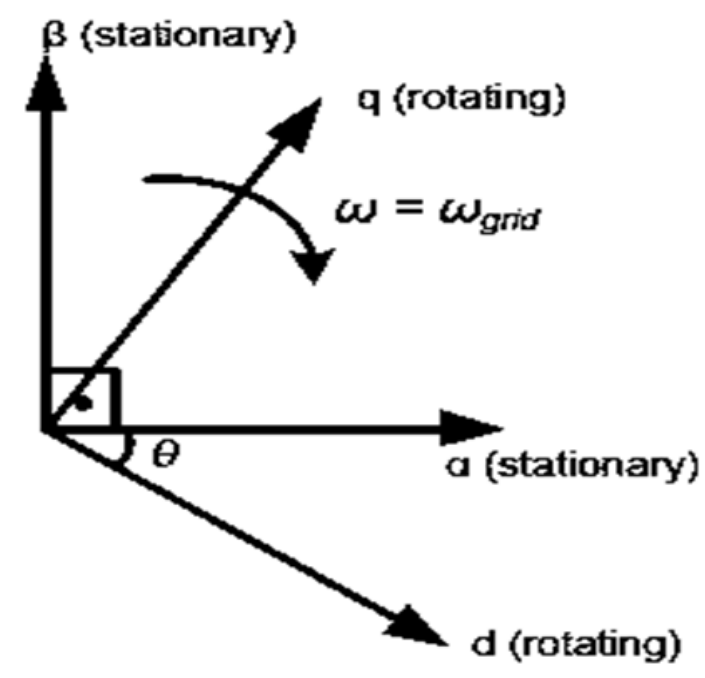

Figure 5. VSC Pulse width modulation vector

$$
\begin{gathered}
\underline{i}_{\alpha \beta}=i_{\alpha}+j i_{\beta} \\
\underline{i}_{d q}=\underline{i}_{\alpha \beta} e^{j \theta} \quad \theta=\int \omega d t
\end{gathered}
$$

Applying equations (6) to (7) to transform the $\alpha \beta$ vectors along the two orthogonal $d q$ axes leads to equation (9), with two unknowns in both equations.

$$
\begin{gathered}
i_{d}=i_{\alpha} \cos \theta+i_{\beta} \sin \theta \\
i_{q}=-i_{\alpha} \sin \theta+i_{\beta} \cos \theta
\end{gathered}
$$

The transformation matrix $\left[T_{d q}\right]$ helps in representing eqn (9) as eqn (10) 


$$
\left[\begin{array}{l}
i_{d} \\
i_{q}
\end{array}\right]=\underbrace{\left[\begin{array}{rr}
\cos \theta & -\sin \theta \\
\sin \theta & \cos \theta
\end{array}\right]}\left[\begin{array}{l}
i_{\alpha} \\
i_{\beta}
\end{array}\right]
$$

\section{$\left[\boldsymbol{T}_{d q}\right]$}

The matrix $\left[T_{d q}\right]$ satisfies the condition of orthogonality given by $\left[T_{d q}\right]^{T}\left[T_{d q}\right]=I_{2 \times 2}$, where $\left[T_{d q}\right]^{T}$ is the transpose of $\left[T_{d q}\right]$ and $I_{2 \times 2}$ is the identity matrix. The transformation expression of equation (10) with an additional sequence component of 0 is known as the Park transformation. The $\alpha \beta$ frame to $d q$ frame normalized transformation creates room for the current vector to be the same in both frames of reference, therefore,

$$
i_{\alpha}^{2}+i_{\beta}^{2}=i_{d}^{2}+i_{q}^{2}
$$

From the proposed two-trap shunt RC damper shown in the model system in Figure 1, the mathematical model based on the $d q$ reference frame could be expressed as $[22,23]$ :

$$
\begin{gathered}
\frac{d}{d t} \underline{i}_{g, d q}=\frac{1}{L_{g r i d}+L_{g}}\left(\underline{V}_{C_{f}, d q}-\underline{E}_{g r i d, d q}-R_{g r i d} \underline{i}_{g, d q}-j \omega\left(L_{g r i d}+L_{g}\right) \underline{i}_{g, d q}\right) \\
\frac{d}{d t} \underline{i}_{c, d q}=\frac{1}{L_{c}}\left(\underline{V}_{c, d q}-\underline{V}_{C_{f}, d q}-j \omega L_{c} \underline{i}_{c, d q}\right) \\
\frac{d}{d t} \underline{V}_{C_{f}, d q}=\frac{1}{C_{f}}\left(\underline{i}_{c, d q}-\underline{i}_{g, d q}-j \omega C_{f} \underline{V}_{C_{f}, d q}\right)
\end{gathered}
$$

It is considerably meaningful for the transformation of the mathematical model into the same frame as the current controllers are in $d q$ frame operation. From equation (12),

$\underline{i} g, d q$ is the grid current vector,

$\underline{i}_{c, d q}$ is the converter current vector,

$\underline{V} g, d q, \underline{V}_{c, d q}$, and $\underline{V} C f, d q$ are the grid voltage vector, the converter output voltage vector and the tilter capacitor current vector, respectively. 


\section{Operating Principle of the Proposed Scheme}

From the model system in Figure 1, the proposed two-trap shunt RC damper is used to reduce multiple harmonic frequencies that are basically above the tuning frequency of the filter by using the capacitors and the tuned inductors. The circuit when tuned, resonates at a fundamental frequency, so that the fundamental current flowing into the resistor could be bypassed. Hence, the proposed two-trap filter has the characteristics of low damping losses and better harmonic attenuation, when operating in combination with a grid connected voltage source converter.

The selection of the parameters of the filter is based on [24], which ensures that the harmonics in the connected grid current are lower than the specified values. The performance of the filter is based on the admittance transfer function represented by the grid current to the converter voltage expressed in equation (13) [24, 25].

$$
Y_{g c}=\left.\frac{i_{g}}{V_{c}}\right|_{V_{g}=0}=\frac{1}{s\left(L_{c}+L_{g}\right)} \frac{\frac{s^{3}}{\omega_{0} \omega_{t}^{2} Q}+\frac{s^{2}}{\omega_{t}^{2}}+(n+1) \frac{s}{\omega_{0} Q}+1}{\frac{s^{4}}{\omega_{0}^{2}}+\left(\frac{n}{\omega_{t}^{3}}+\frac{1}{\omega_{0} \omega_{t}^{2}}\right) \frac{s^{3}}{Q}+\left(\frac{1}{\omega_{0}^{2}}+\frac{1}{\omega_{t}^{2}}\right) s^{2}+(n+1) \frac{s}{\omega_{0} Q}+1}
$$

Equation (13) describes how the modulation control strategy of the harmonic voltage is propagated into the grid current. In equation (13), $\omega_{t}$ is the tuned frequency and $\omega_{0}$ is the characteristic frequency, and they are expressed in equations (14) and (15), respectively as [26]:

$$
\begin{gathered}
\omega_{t}=\sqrt{\frac{1}{n L_{t} C_{f}}} \\
\omega_{o}=\sqrt{\frac{L_{c}+L_{g}}{L_{c} L_{g} C_{f}}}
\end{gathered}
$$

The damping effect in the circuit is determined by the quality factor and it depends on the filter components. This is expressed as

$$
\begin{gathered}
Q=\frac{R_{0}}{R_{d}} \\
R_{0}=\sqrt{\frac{L_{c} L_{g}}{\left(L_{c}+L_{g}\right) C_{f}}}
\end{gathered}
$$


Theoretically, a trap filter produces infinite attenuation at the switching frequency, and at frequencies above the switching frequency, the filter attenuation rapidly decreases. Based on the above features and analysis, the two-trap shunt RC damper will give a good damping performance of the variables of a grid connected VSC system during network disturbance.

\section{Evaluation of the Model System Performance}

Simulations were run for 600 seconds for dynamic analysis considering the model system in Figure 1 using natural wind speed obtained from Hokkaido Island, Japan as shown in Figure 6. Three scenarios were considered. In the first scenario, no grid frequency control was implemented in the model system. The second scenario uses the conventional energy capacitor system for stability of the grid frequency. In the third scenario, the proposed two-trap shunt RC damper was used to further enhance the performance of the energy capacitor system and the entire power network. Some of the simulation results in PSCAD/EMTDC are discussed as follows for the model system variables.

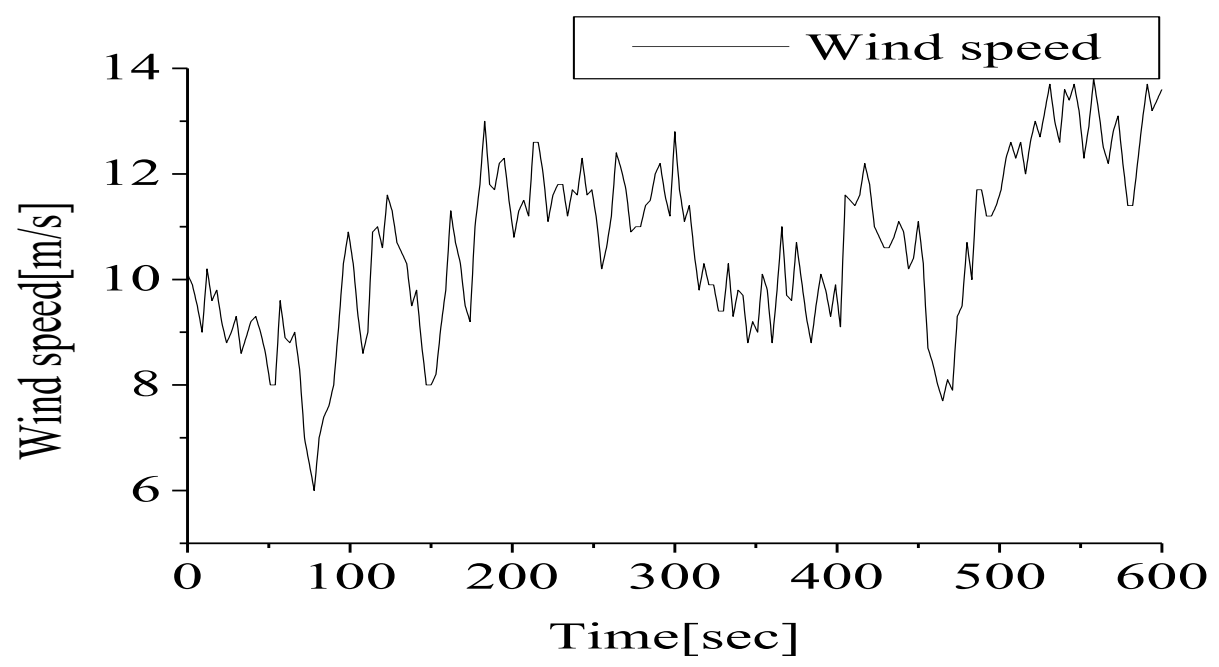

Figure 6. Wind speed data for system analysis

Figure 7 shows the response of the grid frequency considering three scenarios. When no control was implemented, the grid frequency was distorted due to the stochastic nature of the natural wind energy in Figure 6. Hence, the grid codes require the wind farm to be shut down in this case to avoid damage to the power network and utilities connected to it. With the help of the energy capacitor system control strategy, active power control was achieved, in addition to reactive power that was injected into the grid network based on the coordinated control of the ECS Pulse Width Modulation DC chopper presented in Figure 2. The grid frequency was controlled almost within the permissible limit set by the grid codes in order to avoid shutting down of the wind farm considering an LPF time constant of 120 seconds. In a bid to further improve the grid frequency performance of the network, the proposed control scheme with the two-trap shunt RC damper was used as shown in Figure 7. The two-trap RC shunt damper helped 
boost the grid frequency during dynamics by damping the system and also filtering the attenuated harmonics based on the analysis presented earlier in this paper.

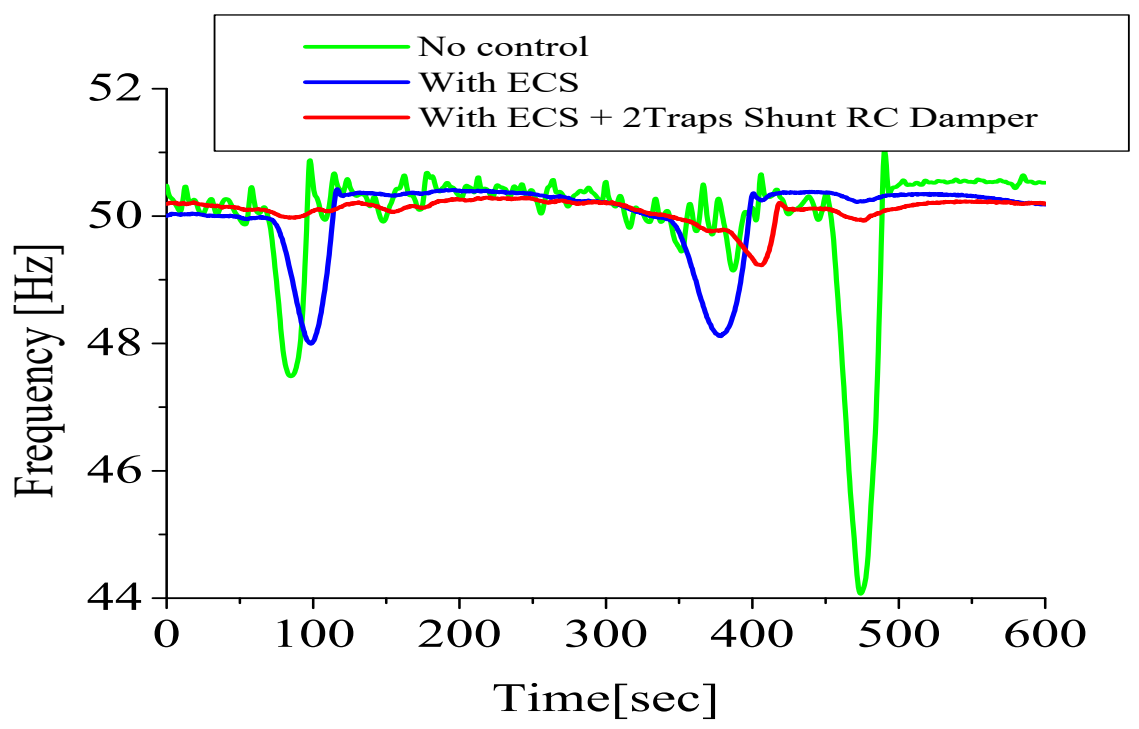

Figure 7. -requency response ot the grid network

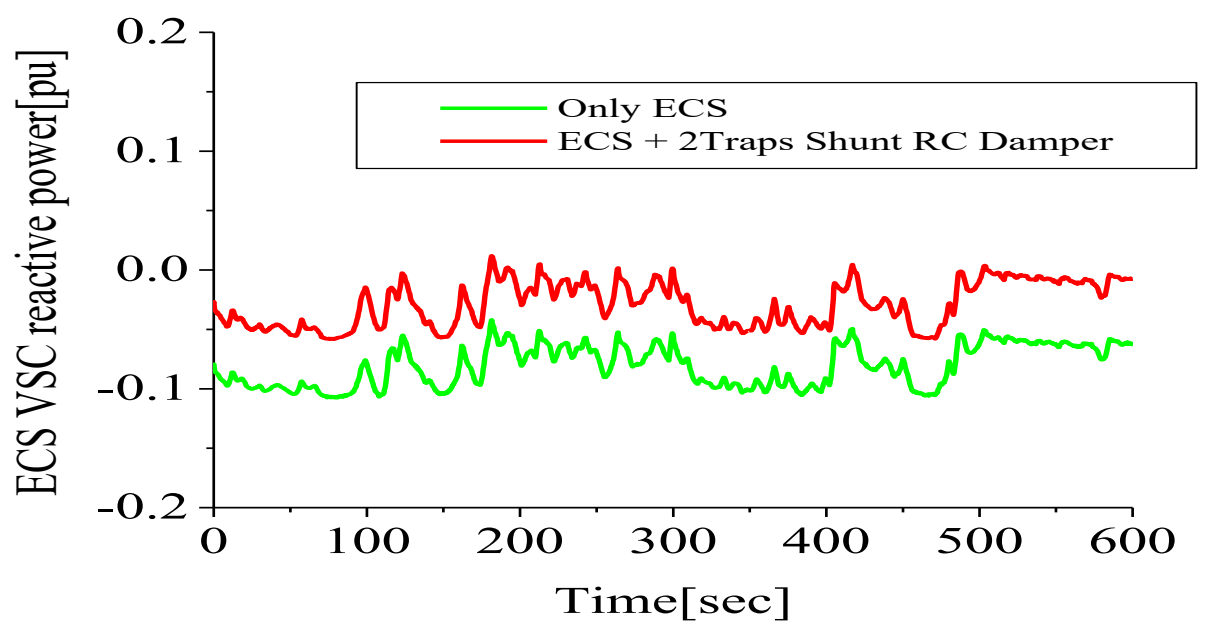

Figure 8. Reactive power of energy capacitor system

Figure 8 shows that the proposed coordinated control topology is able to boost the reactive power production of the ECS grid connected VSC to help in further stabilizing the grid system with faster recovery of the grid variables. This is because the proposed control will increase the mechanical power extracted from the drive train of the wind turbine, thus reducing its speed excursion during grid disturbances as shown in Figure 9 for the wind turbine speed. Moreover, based on the fact that mechanical torque is proportional to the square of the stator voltage of the wind generator, the effect would enhance the recovery of the wind turbine after the grid dynamics. 


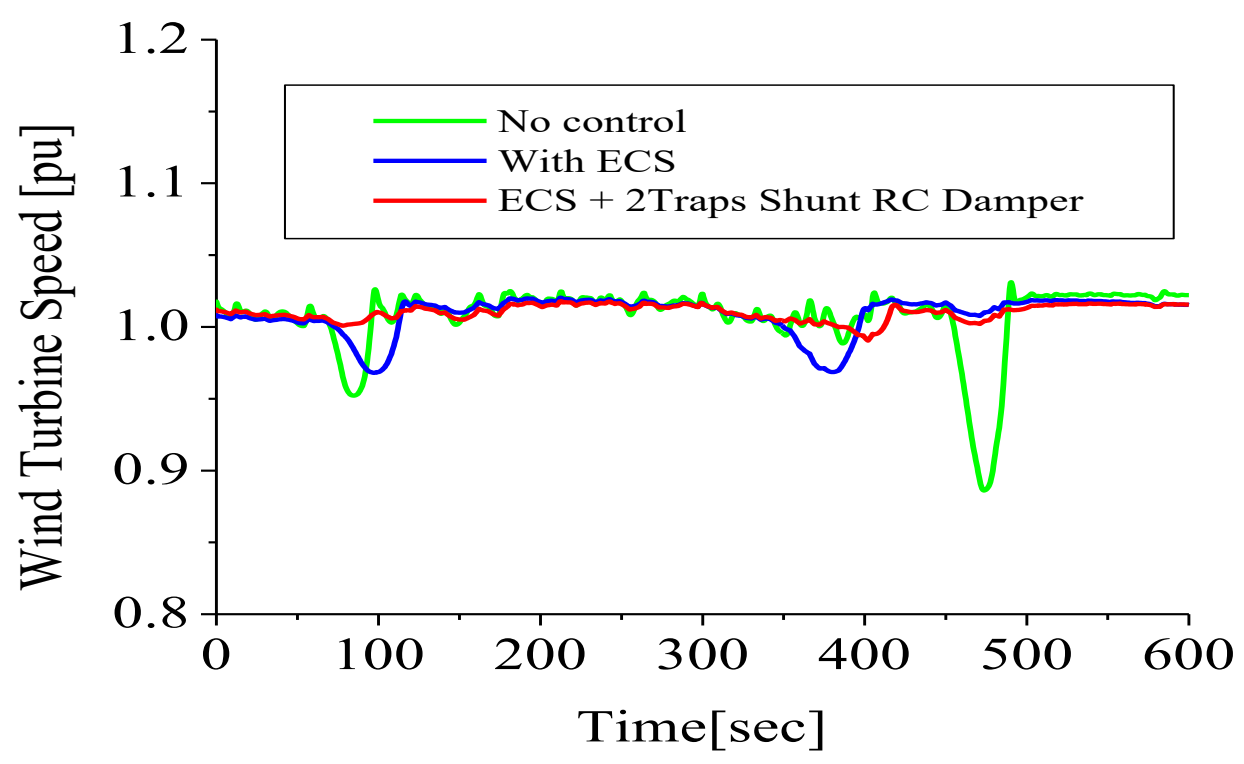

Figure 9. Wind turbine speed

\section{CONCLUSIONS}

In this paper, a more efficient coordination of voltage source converter energy capacitor based system and two-trap shunt RC damper is proposed to enhance the performance of the frequency of a grid network during dynamic conditions. The working principle of the pulse width modulation voltage source converter and the operation principle of the proposed two-trap shunt RC damper were presented. The simulation results show that the proposed control strategy was able to enhance not only the grid frequency, but other variables of the network by boosting the performance of the energy capacitor system during grid disturbances. Also, with this topology, wind farms would remain connected to the grid network during grid disturbances because the permissible limit of operation of the grid frequency would be met based on the stipulated grid requirements.

\section{CONFLICTS OF INTEREST}

The author declares that there is no conflict of interests regarding the publication of this paper.

\section{REFERENCES}

[1] Popović-Gerber, J., Oliver, J. A., Cordero, N., Harder, T., Cobos, J. A., Hayes, M., O'Mathuna, S. C., Prem, E. (2012). Power electronics enabling efficient energy 
usage: energy savings potential and technological challenges. IEEE Trans. Power Electronic. 27(5), $2338-2353$.

[2] Okedu, K. E. (2016). Enhancing DFIG wind turbine during three-phase fault using parallel interleaved converters and dynamic resistor. IET Renewable Power Generation. 10 (6), 1211-1219.

[3] Okedu, K. E., Muyeen, S. M., Takahashi R., and Tamura, J. (2011). Protection schemes for DFIG considering rotor current and DC-link voltage. 24th IEEEICEMS (International Conference on Electrical Machines and System), Beijing, China, 1-6. DOI: 10.1109/ICEMS.2011.6073453

[4] Ramesh S., and Krishnan, A. (2011). Stabilization of frequency deviation in an ACDC interconnected power systems using supervisory fuzzy controller. Tamkang Journal of Science and Engineering. 14(4), 341-349.

[5] Gross, G., and Lee J. W. (2001). Analysis of load frequency control performance assessment criteria. IEEE Transactions on Power Systems. 16, 520-525.

[6] Venkata P. B., Jayaram K. S. V. (2008) Load frequency control for two area interconnected power system using robust genetic algorithm controller. Journal of theoretical and applied information technology. 4(12), 1204-1221. http://www.jatit.org/volumes/research-papers/Vol4No12/7Vol4No12.pdf (accessed on $6 / 1 / 2018$ )

[7] Hulst, D., Fernadez, M., et al. (2015). Voltage and frequency control for future power systems: the Electra IRP Proposal. Proceedings International symposium in smart electric distribution systems and technologies, 245-250. DOI: 10.1109/SEDST.2015.7315215

[8] Jagathessan K., and Dey N. (2015). Artificial intelligence in performance analysis of load frequency control in thermal wind hydropower system. International Journal of Advanced Computer Science and Applications. 6 (7), 203-212.

[9] Messikh, T., Mekhilef S., and Rahim, N. A. (2008). Adaptive notch filter for harmonic current mitigation. World Academy of Science Engineering and Technology. 22, 907-913.

[10] Saiteja K., and Krishnarayalu, M. S. (2015). Load frequency control of two area smart grid. International Journal of Computer Applications. 117(14), 1-9.

[11] Wilches-Bernal F., Chow, J. H., and Sanchez-Gasca, J. J. (2015). A fundamental study of applying wind turbines for power system frequency control. IEEE Transactions on Power Systems. 31(2), 1496-1505.

[12] Liserre, M., Blaabjerg, F., and Hansen, S. (2005). Design and control of an LCLfilter-based three-phase active rectifier, IEEE Trans. on Ind. Applications. 41(5), 1281-1291.

[13] Patel, Y., Pixler, D., and Nasiri, A. (2010). Analysis and design of trap and LCL filters for active switching converters. IEEE Int. Symp. on Ind. Electron. 638-643. DOI: 10.1109/ISIE.2010.5637475

[14] Dannehl, J., Liserre, M., and Fuchs, F. W. (2011). Filter-based active damping of voltage source converters with LCL filter. IEEE Trans. Ind. on Electronic. 58(8), 3623-3633.

[15] Teodorescu, R., Blaabjerg, F., Liserre, M., and Dell'Aquila, A. (2003). A stable three-phase LCL-filter based active rectifier without damping. 38th IAS Annual Meeting on Conference Record of the Industry Applications Conference, 3, 15521557. DOI: 10.1109/IAS.2003.1257762 
[16] Beres, R., Wang, X., Blaabjerg, F., Bak, C. L., and Liserre, M. (2014). A review of passive filters for grid-connected voltage source converters. 2014 IEEE Applied Power Electronics Conference and Exposition - APEC 2014. 2208-2215. DOI: 10.1109/APEC.2014.6803611

[17] Friedrich L., and Gautschi, M. (2009). Grid stabilization control and frequency regulation for inverted connected distribution renewable source. Master Thesis, Department of Electrical and Computer Engineering, Power System Research, University of Wisconsin- Madison.

https://pdfs.semanticscholar.org/b478/00585681f7880da0c2b7ae02222efca9cf78.pd $\underline{f}$ (accessed on 6/1/2018)

[18] Okedu, K. E. (2017). Effect of ECS low pass filter timing on grid frequency dynamics of a power network considering wind energy penetration. IET Renewable Power Generation. 11(9), 1194-1199.

[19] Okedu, K. E. (2017). Improving grid frequency dynamics of synchronous generators considering wind energy penetration. IEEE International Electric Machines and Drives Conference (IEMDC), Paper ID 112, May 21-24, Miami, Florida, USA. DOI: 10.1109/IEMDC.2017.8001865

[20] Okedu, K. E., Muyeen, S. M., Takahashi, R., and Tamura, J. (2012). Wind farms fault ride through using DFIG with new protection scheme. IEEE Transactions on Sustainable Energy. 3(2), 242-254, April. DOI: 10.1109/TSTE.2011.2175756

[21] Manitoba HVDC research center, (2004). PSCAD/EMTDC Manuals. https://hvdc.ca/uploads/knowledge base/pscad users_guide v4 6.pdf?t=14975342 $\underline{32}$, and https://hvdc.ca/uploads/knowledge_base/emtdc_users_guide_v4_6.pdf?t=14975341 78 (accessed on $6 / 1 / 2018$ )

[22] Usluer, S. N. (2014). Switch mode converter based damping of PWM converter with LCL type filter for grid interface of renewable energy. Thesis, Natural and Applied Science, Middle East Technical University. http://etd.lib.metu.edu.tr/upload/12618359/index.pdf (accessed on 6/1/2018)

[23] Beres, R., Wang X., and Blaabjerg, F. (2015). Improved passive-damped LCL filter to enhance stability in grid-connected voltage source converters. Proceedings of the 23rd International Conference and Exhibition on Electricity Distribution, Lyon France, 15-18 June, Paper 1093.

[24] IEEE. (1993). IEEE Recommended Practices and Requirements for Harmonic Control in Electrical Power Systems. IEEE Std 519-1992, 1-112. https://ieeexplore.ieee.org/document/210894/ (accessed on 6/1/2018)

[25] Dugan, R. C. McGranaghan, M. F., Santoso, S., Beaty, H.W. (2012). Electrical power systems quality, Mc Graw Hill, New York, United States of America, 290.

[26] Wu, W., He, Y., and Blaabjerg, F. (2012). An LCL power filter for single-phase grid-tied inverter. IEEE Trans. on Power Electronic. 27(2), 782-789.

Article copyright: (C) 2018 Kenneth E. Okedu. This is an open access article distributed under the terms of the Creative Commons Attribution 4.0 International License, which permits unrestricted use and distribution provided the original author and source are credited. 